\title{
Downsizing: policy options to reduce portion sizes to help tackle obesity
}

The artwork supplied by the CDC for figure 1 in this Analysis (BMJ 2015;351:h5863, doi: 10.1136/bmj.h5863) omitted the data sources. The citations are Young L, Nestle M. The contribution of expanding portion sizes to the US obesity epidemic. Am J Public Health 2002;92:246-9 and Young L,
Nestle M. Portion sizes and obesity: responses of fast food companies. J Public Health Policy 2007;28:238-48.

Cite this as: BMJ 2016;352:1105

๑) BMJ Publishing Group Ltd 2016 